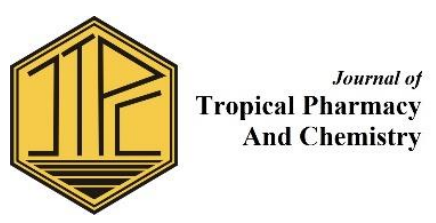

\title{
EFFECTIVENESS USUAL COUNSELING BY PHARMACIST OF RSUD A.W. SJAHRANIE SAMARINDA TO IMPROVE MEDICATION COMPLIANCE IN HYPERTENSION
}

\author{
Welinda Dyah Ayu*,Victoria Yulita Fitriani, Dewi Rahmawati \\ Faculty of Pharmacy, Mulawarman University, Samarinda, East Borneo, Indonesia \\ *Email: welinda@farmasi.unmul.ac.id
}

\begin{abstract}
Compliance to antihypertensive medications represents a success factor for blood pressure control in clinical practice. Medical non-compliance has been identified as a major public health problem in the treatment of hypertension. This study evaluated an additional usual counselling could achieve optimal BP control. This experimental study uses cohort study design using prospective patient data collection in patients with hypertension, and hypertension with complications at RSUD A.W.Sjahranie, Samarinda from July 2014October 2014. Data were collected by interviews and questionnaires; meanwhile the patient's blood pressure data were taken from the medical record. A total of 61 patients. The results showed that there were not significant different in change BP control and compliance level wilcoxcon ( $\mathrm{p}>0,05$ ). The compliance status in usual counselling relatively poor. Phamacist counselling are important to improve medication compliance in hypertension.
\end{abstract}

Keywords: counseling, hypertension, questionnaires

Submitted on: 3 July 2018

Accepted on: 1 August 2018

DOI: https://doi.org/10.25026/jtpc.v4i3.172

\section{INTRODUCTION}

Hypertension causes $4.5 \%$ of the global burden of disease, and its prevalence is nearly as large in developing countries and in developed countries [1]. The success of a treatment is influenced by patients' compliance which will not achieve the therapeutic results of the optimal level in the absence of awareness of the patients' own [2]. Effective drug therapy will happen if patients are given enough information about medication commonly known by counseling [3]. One of the benefits of counseling is to improve patient compliance in medication usage, maximizing the use of the medicines so that the mortality rate can be reduced [4].

Hypertensive patients are one of the patients with criteria which must be counseled, because hypertension is a disease that is very slowly attacking if not recognized and treated well, hypertension 
may result in death. Thus regular blood pressure checks have an important significance in the treatment of hypertension. Lack of patients' compliance is also an issue in hypertension treatment [5]. Patients with hypertension are not aware of the characters that up and down. When the patient is stated to be able to stop taking medications because his/her blood pressure gets back to normal, he/she often thinks that he/she has been permanently cured. Whereas, once someone is convicted of hypertension, the disease will remain forever. What can be done to control the hypertension is by taking hypertension - lowering drugs and live a healthy lifestyle [6].

Hypertensive patients may have no symptoms for years. This latency period covers the development of the disease until significant organ damages occur. If there are symptoms that are usually nonspecific such as headaches or dizziness, early detection and effective treatment of hypertension can reduce the number of morbidity and mortality. Thus, a more comprehensive and intensive approach is needed to achieve optimal blood pressure control [7].

\section{METHOD}

This study uses a cohort design to capture patient data prospectively in patients with hypertension, and hypertension with complications in the polyclinic of internal disease of RSUD A.W. Sjahranie Samarinda from May to July 2014. A total of 260 patients consisted of 50 patients were validation, 70 patients were usual counseling which follow the intervention group were 61 patients of which hypertensive patients given counseling. Another 140 patients were used for other research category. Criteria of inclusion were adult patients, both men and women aged between 18-65 years old, diagnosed with prehypertension, hypertension levels I and II with or without complications, getting antihypertensive drugs, not pregnant and not illiterate. Instrumentation used were interviews and questionnaires with the patients' blood pressure data taken from the medical record. The instrument taken with Medication Adherence Measure in an Outpatient Setting [8].

\section{RESULT AND DISCUSSION}

In this study, there are some lifestyle characteristics of the patients described in the patient demographic data consisting of a control group and the intervention group that were given a check list schedule reminders. Testing were conducted with Spearman analysis with a result of $p>0.05$, which indicates no significant difference, as shown in Table 1.

The level of hypertension was assessed at the beginning when patients took a part in the study, that was the systolic blood pressure measured for the first time in the RSUD A.W. Sjahranie Samarinda for treatment. Differences and the effect of counseling on changes in systolic blood pressure, compliance were observed in this study.

Normality test for systolic blood pressure in this study showed that the usual counseling group data were normally distributed ( $\mathrm{p}<0.05)$ so as to see whether there was a depresion in systolic blood pressure in the usual counseling group, differenciate test Wilcoxon Signed Rank Test were used. Of the average systolic blood pressure of the patients before and after counseling was no significant difference in systolic blood pressure scores in the patsients both pre and post - visit with a significance score of $p=0.09$ Poor adherence is a challenge for clinicians to decide which treatment is more effective. Many factors reported 
affect adherence negatively, such as neglect, depression, complex treatment regimens, patients' perception of the health care system, and medicines' side effects and the lack of knowledge about hypertension and medicine treatment.

Compliance of patients in hospitals A.W. Sjahranie Samarinda before the usual counseling pharmacists data used wilcoxcon test patients are given pre- visit questionnaire MMAS at the first visit patients and post when the next visit.

In Figure 1 it can be seen that the patients in the group previsit has moderate compliance as much as $26 \%$ and as much as $54 \%$ lower compliance .

Table 1. Patients' Demographic Data

\begin{tabular}{lcc}
\hline \multirow{2}{*}{ Characteristics } & \multicolumn{2}{c}{ Usual Counseling } \\
Sex & Number of people $(\mathrm{n}=61)$ & $\%$ \\
\hline Male & 34 & 55,7 \\
Female & 27 & 44,3 \\
\hline Age (years old) & 2 & \\
\cline { 1 - 1 } $26-35$ & 4 & 3,3 \\
$36-45$ & 23 & 6,6 \\
$46-55$ & 32 & 37,7 \\
$56-65$ & & 52,5 \\
\hline Education & 26 & \\
\hline $0-9$ years & 23 & 42,6 \\
$10-12$ years & 12 & 37,7 \\
$>12$ years & & 19,7 \\
\hline Smoking Habit & 6 & 9,8 \\
\hline Yes & 55 & 90,2 \\
No & & \\
\hline
\end{tabular}

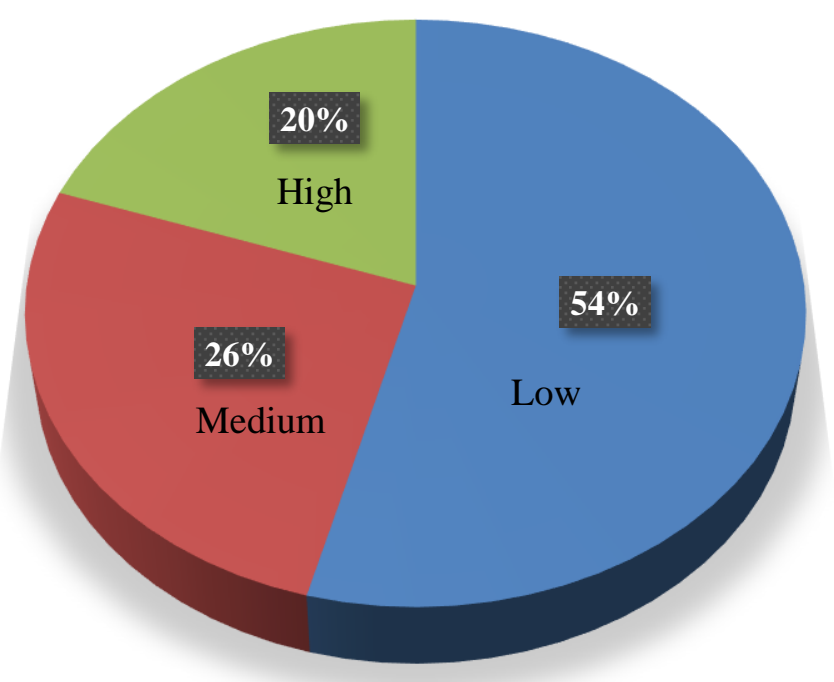

Figure 1 Patient Compliance Pre-Visit 


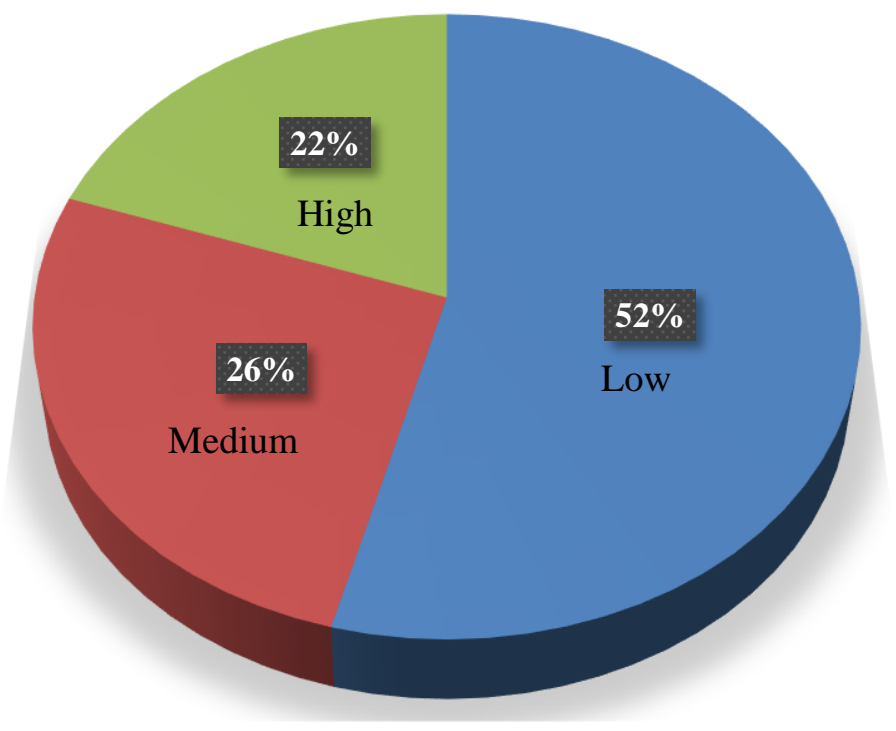

Figure 2 Patient Compliance Post - Visit

Figure 2 shows an increase in compliance after post usual-counselling by pharmacists in A.W. Sjahranie hospitals and it gained significance 0.329 . It can be seen the values obtained significance of greater value than $\alpha=$ 0.05 , which means that there is no significant difference between the average ranking MMAS pre-visit and post-visit. So it was concluded that the usual counselling conducted by a hospital pharmacist of A.W. Sjahranie Hospital has no effect on patient compliance.

With the pharmaceutical counseling, patients were given the understanding that hypertension could not be cured and if the blood pressure does not reach the targets set, it will cause damages to other organs. Efforts made to the hypertensive patients are taking antihypertensive medicines to lower blood pressure to the target set and the patients will always need medication to control their blood pressure.

\section{CONCLUSION}

Overall, it can be concluded that compliance status in usual counseling relatively poor. Phamacist counseling are important to improve medication compliance in hypertension.

\section{REFERENCES}

[1] WHO, 2003, International Society of Hypertension Writing Group, World Health Organization-International Society of Hypertension statement of Management of Hypertension. pp 108-17.

[2] Hussar, DA., 1995. Patient Compliance in Remington; The Science and Practice of Pharmacy, The Philadelphia College of Pharmacy and Science, USA, pp :vol 2:1796-1807

[3] Cipolle, R.J, Strand, L.M, Morley, P.C. 2004, Pharmaceutical Care Practice: the Clinician's Guide (2th Ed). New York. The McGrow Hill $\mathrm{CO}$ 
[4] Schnipper, JL, Jennifer, LK, Michael, CC, Stephanie, AW, Brandon, AB, Emily, T, Allen, K, Mark, H, Christoper, LR, Sylvia, CM, David, WB. 2006. Role of Pharmacist Counseling in Preventing Adverse Drug Events after Hospitalization. USA: Archives of Internal Medicine. Vol 166.565-571.

[5] Onzenoort, H.A.W. 2010. Assesing Medication Adherence Simultaneously by Electronic Monitoring and Pill Count in Patients with Mild to Moderate Hypertension. USA: American Journal of Hypertension. 23, 149-154.
[6] Price, SA dan M. W. Lorraine. 1994. Patofisiologi : Konsep Klinis ProsesProses Penyakit, Edisi IV Jilid I, Jakarta : Penerbit Buku Kedokteran EGC.

[7] Brown, C.T., 2006, Penyakit Arteroskerotik Koroner, dalam: Price, S. A., Wilson, L. m., (eds): Patofisiologi, Volume I, Edisi VI, Jakarta: Penerbit Buku Kedokteran EGC, hal. 582-84.

[8] Morisky, D.E., Ang A, KrouselWood, M.A., Ward H, 2008, Predictive Validity of A Medication Adherence Measure in an Outpatient Setting, J. Health-Syst. Pharm, 10:348-54.

How to cited this article :

Ayu, W.D., Fitriani, V.Y., Rahmawati, D., 2018. Effectiveness Usual Counseling by Pharmacist of RSUD A.W. Sjahranie Samarinda to Improve Medication Compliance in Hypertension. J. Trop.Pharm. Chem. 4(3); 142-146. 